PAPER

\title{
The generic 15D instrument is valid and feasible for measuring health related quality of life in Parkinson's disease
}

\author{
T H Haapaniemi, K A Sotaniemi, H Sintonen, E Taimela for the EcoPD Study Group
}

J Neurol Neurosurg Psychiatry 2004;75:976-983. doi: 10.1136/jnnp.2003.015693

See end of article for authors' affiliations

avthe affiliations

Correspondence to: Dr T Haapaniemi, Department of Neurology,

Oulu University Hospital,

PO Box 25, 90029 Oulu,

Finland;

tarja.haapaniemi@oulu.fi

Received 14 April 2003

In revised form

25 August 2003

Accepted

18 November 2003

idity and feasibility of the generic 15D health related quality of life (HRQoL) Objectives: To test the validity and feasibility of the generic 15D health related quality of life (HRQoL)
instrument in Parkinson's disease (PD) and compare parkinsonian patients with the general population. Much effort has gone into developing disease specific HRQoL measures for PD, but only generic measures allow comparisons with the general population. New HRQoL tools are needed for PD because earlier ones have low feasibility in elderly patients.

Methods: The study comprised 260 patients with idiopathic PD and age and sex matched controls. HRQoL was evaluated using the disease specific questionnaire PDQ-39 and the 15D generic instrument. PD severity was assessed by Hoehn and Yahr staging, and the activities of daily living (ADL) and motor section of the Unified Parkinson's Disease Rating Scale (UPDRS).

Results: The mean 15D score (scale 0-1; overall HRQoL) was lower in PD (0.77) than in controls (0.86). Patients with PD had significantly lower scores than controls in 13 of the 15 dimensions of 15D. Scores of the corresponding dimensions of PDQ-39 and 15D correlated significantly, confirming the convergent validity of $15 \mathrm{D}$. In multiple stepwise regression analysis, the UPDRS ADL score explained $55 \%$ of the variation in the $15 \mathrm{D}$ score.

Conclusions: 15D is a valid, feasible, and sensitive tool to assess quality of life in PD. PD has a major impact on HRQoL, which is related to disease progression. Mobility, eating, speech, and sexual functions are most affected. The ADL measure of the UPDRS and the 15D provide an easily assessable view of HRQoL in PD.

$\mathrm{P}$ arkinson's disease (PD) is a chronic neurodegenerative disorder characterised by motor symptoms such as bradykinesia, resting tremor, rigidity, and disturbances of balance. In addition to motor disability, patients with PD may experience depression, cognitive dysfunction, autonomic symptoms, and as the disease proceeds, many patients develop treatment related motor fluctuations and dyskinesias. The manifold symptomatology in PD obviously compromises physical, psychological, and social well being.

The emphasis in the development of tools for assessing the impact of PD on health related quality of life (HRQoL) has been on disease specific evaluative instruments. ${ }^{1}$ These are designed to obtain more detailed information on the areas of quality of life affected by the disease, and the impact of treatment can be evaluated more easily using these instruments than with generic approaches. ${ }^{2}$ The most widely used PD specific HRQoL evaluative tools are the 39 item Parkinson's Disease Questionnaire (PDQ-39) ${ }^{3}{ }^{4}$ and the 37 item Parkinson's Disease Quality of Life Questionnaire (PDQL). ${ }^{5}$ Several studies ${ }^{367}$ have shown that the severity of the disease measured by the Unified Parkinson's Disease Rating Scale (UPDRS) ${ }^{8}$ and Hoehn and Yahr stage ${ }^{9}$ correlates with impaired HRQoL. Depression and cognitive impairment also seem to have a major impact on the HRQoL in parkinsonian patients. ${ }^{10}$

Complementing the disease specific evaluations, generic instruments allow comparisons across health conditions and some of them, namely preference based instruments, can be used in health economic studies. The Nottingham Health Profile and the medical outcomes study short form (SF-36) have been used in patients with PD. ${ }^{6}{ }^{10-12}$ However, these instruments are laborious to complete and may have feasibility problems in elderly patients. The $15 \mathrm{D}$ is a 15 dimensional, standardised generic HRQoL instrument that can be used both as a profile and a single index score measure. ${ }^{13-15}$

To compare the HRQoL in patients with PD with the general population we examined the validity and feasibility of the 15D instrument in parkinsonian patients and in control subjects from a community based sample. We also aimed to evaluate the impact of various parkinsonian symptoms and clinical findings on HRQoL, in addition to the influence of associated factors, such as depression, cognitive dysfunction, disease duration, and dyskinesias. Because HRQoL instruments are unfamiliar to most clinicians and therefore seldom used in daily practice we also tested whether the UPDRS or its subdivisions can be applied to predict HRQoL in PD.

\section{METHODS}

\section{Patients}

Two hundred and sixty consecutive outpatients with PD in six neurological centres were included in our study. All patients were examined by an experienced neurologist and diagnosed to have probable idiopathic PD according to the UK Brain Bank criteria. ${ }^{16}$ Patients who had participated in a clinical drug trial during the past 12 months or used catechol$O$-methyl transferase inhibitors (costs not compensated by the health insurance at the time point of our study) were excluded because the study was part of a project assessing the

Abbreviations: $A D L$, activities of daily life; $H R Q$ quality of life; PD, Parkinson's disease; PDQ-39, 39 item Parkinson's Disease Questionnaire; PDQL, Parkinson's Disease Quality of Life Questionnaire; SF-36, medical outcomes study short form; UPDRS Unified Parkinson's Disease Rating Scale 
economic burden to the society caused by PD and the data were to be used in a cost effectiveness model for such treatment. ${ }^{17}$ Our study was approved by the local ethical committees at each centre.

\section{Study design}

Patients were recruited at their routinely scheduled clinical follow up visits at each centre so that they were representative of patients with PD in the common health care practice in Finland, where specialists in neurology carry the major responsibility for their treatment. After the patients had given their written consent, clinical and neurological examinations were performed at a single visit. The patients completed the HRQoL questionnaires either during the visit or at home.

\section{Clinical assessment}

The severity of the disease was assessed during "on" stage with the modified Hoehn and Yahr staging, the UPDRS activities of daily living (ADL) and motor scores, and the Schwab and England ADL scale. The severity of resting tremor was calculated as the sum of item 20 and the severity of rigidity as the sum of item 22 . The severity of problems of speech was scored by item 18, gait by item 29, postural stability by item 30 , and the severity of hypokinesia by item 31. A structured interview included questions dealing with the duration of PD symptoms, the time elapsed since PD was diagnosed, duration and dosage of levodopa treatment, other current treatment for PD, and the presence of concomitant diseases. The investigators evaluated whether the patient had depression or dementia fulfilling the DSM-IV criteria (graded as none, mild, moderate, or severe). ${ }^{18}$ The presence or absence of motor fluctuations was recorded.

A control group of 2729 age and sex matched subjects was randomly selected from the National Population Register. The control group is a subset of the representative population sample of the Finnish 1995-1996 Health Care Survey covering the non-institutionalised population aged over 15 years. ${ }^{19}$ Individuals with dementia, stroke, parkinsonism, and other neurological disorders are included in the sample in proportion to their prevalence in that population.

\section{Evaluation of the quality of life}

The HRQoL was assessed cross sectionally using the self completed generic 15D questionnaire (appendix) in the patients with PD and the control subjects ${ }^{13-15}$ and the disease specific PDQ-39 instrument in the patients with PD. ${ }^{4}$ The 15D instrument is a generic, multidimensional, standardised, self administered evaluative tool of HRQoL that can be used primarily as a single index measure, but also as a profile measure. ${ }^{13-15}$ It describes the health status, assessing 15 dimensions, namely: mobility, vision, hearing, breathing, sleeping, eating, speech, elimination, usual activities, mental function, discomfort and symptoms, depression, distress, vitality, and sexual activity. Each dimension comprises one question with five answer options. A single index score (the $15 \mathrm{D}$ score) is obtained by incorporating population based preference weights to the dimensions. This health index on a $0-1$ scale has been used successfully in several pharmacoeconomic evaluations. ${ }^{15}$ The maximum score is 1 (no problems on any dimension) and the minimum score is 0 (being dead). ${ }^{14}{ }^{15}$ The $15 \mathrm{D}$ instrument has good test-retest reliability, construct validity, and discriminatory power in general populations. ${ }^{15}$ It also seems to be highly responsive to treatment related change, as demonstrated-for example, in patients with acute low back pain, ${ }^{20}$ asthma, $^{21}$ chronic obstructive pulmonary disease, ${ }^{22}$ and in those who have undergone hip replacement. ${ }^{15}$
As a disease specific instrument of HRQoL we used the Finnish translation of the PDQ-39, which is a well known measure of HRQoL in PD, comprising 39 questions with five answer options. PDQ-39 has eight subscales, namely: mobility, ADL, emotional well being, stigma, social support, cognitions, communication, and bodily discomfort. The result can be expressed either as a summary score of the items of each subscale or as a total score transformed linearly to a 0-100 scale, with higher scores reflecting lower HRQoL. The PDQ-39 has a well established construct validity and a moderate content validity. ${ }^{323}$ In addition, the internal consistency of the subscales is adequate and the reproducibility of the subtests is good, except for the social support subscale. ${ }^{4}$ The PDQ-39 seems to be capable of detecting disease deterioration but responsiveness to improvement still needs assessment. ${ }^{24}$

\section{Statistical analysis}

Regression analysis was used to predict and replace missing data on the 15D questionnaires by having the dimension with missing data as the dependent variable and the other dimensions, age, sex, and other characteristics of the respondents as independent variables. ${ }^{13}$ No imputation of missing data was carried out for the PDQ-39 questionnaires.

Summary scores and scores for dimensions of the quality of life instruments were calculated according to the scoring algorithms of the HRQoL measures. ${ }^{415}$ HRQoL scores between patients with PD and control subjects were compared using the Mann-Whitney U test. The associations between variables were measured using Pearson and Spearman's rank correlation coefficients. The elements of the UPDRS motor score were considered potential prognostic variables for HRQoL. Stepwise regression analysis was used to determine the factors that best predicted the variance in HRQoL scores and to rule out interaction effects among the explanatory variables. Variables were added one by one to the model with entry and stay at significance values of 0.15 . At the beginning the dependent variables were: the 15D score, all the 15D dimensions, the PDQ-39 dimensions, and single index. The explanatory variables were age, sex, concomitant diseases, depression, dementia, mode of living (alone or not), duration of PD symptoms, the ADL and motor scores of the UPDRS, items 18, 20, 22, 29, 30, 31 of the UPDRS, the Schwab and England score, presence of motor fluctuations, and the Hoehn and Yahr stage. First, the normality and

Table 1 Patient characteristics $(n=259)$

\begin{tabular}{lll}
\hline & N & $\%$ \\
\hline Mean (SD) age in years & $66.5(10.6)$ & \\
Sex (M/F) & $137 / 122$ & $53 / 47$ \\
Mean (SD) disease duration in years & $4.3(4.4)$ & \\
Mean (SD) age at onset in years & $60.4(10.8)$ & \\
Concomitant diseases & 184 & 71.0 \\
Depression & 74 & 28.6 \\
Dementia & 25 & 9.7 \\
Hoehn and Yahr stage & 1 & 0.4 \\
0 & 47 & 18.1 \\
1 & 39 & 15.1 \\
1.5 & 69 & 26.6 \\
2 & 39 & 15.1 \\
2.5 & 42 & 16.2 \\
3 & 22 & 8.5 \\
4 & 0 & 0 \\
5 & 24.1 (12.0) \\
Mean (SD) UPDRS motor score & 10.2 (6.5) \\
Mean (SD) UPDRS ADL score & 82.6 & \\
Mean Schwab and England score & 74 & 28.5 \\
Motor fluctuations & \multicolumn{2}{l}{} \\
\hline ADL, activities of daily life; UPDRS, Unified Parkinson's Disease Rating \\
Scale. \\
\multicolumn{4}{l}{} \\
\hline
\end{tabular}




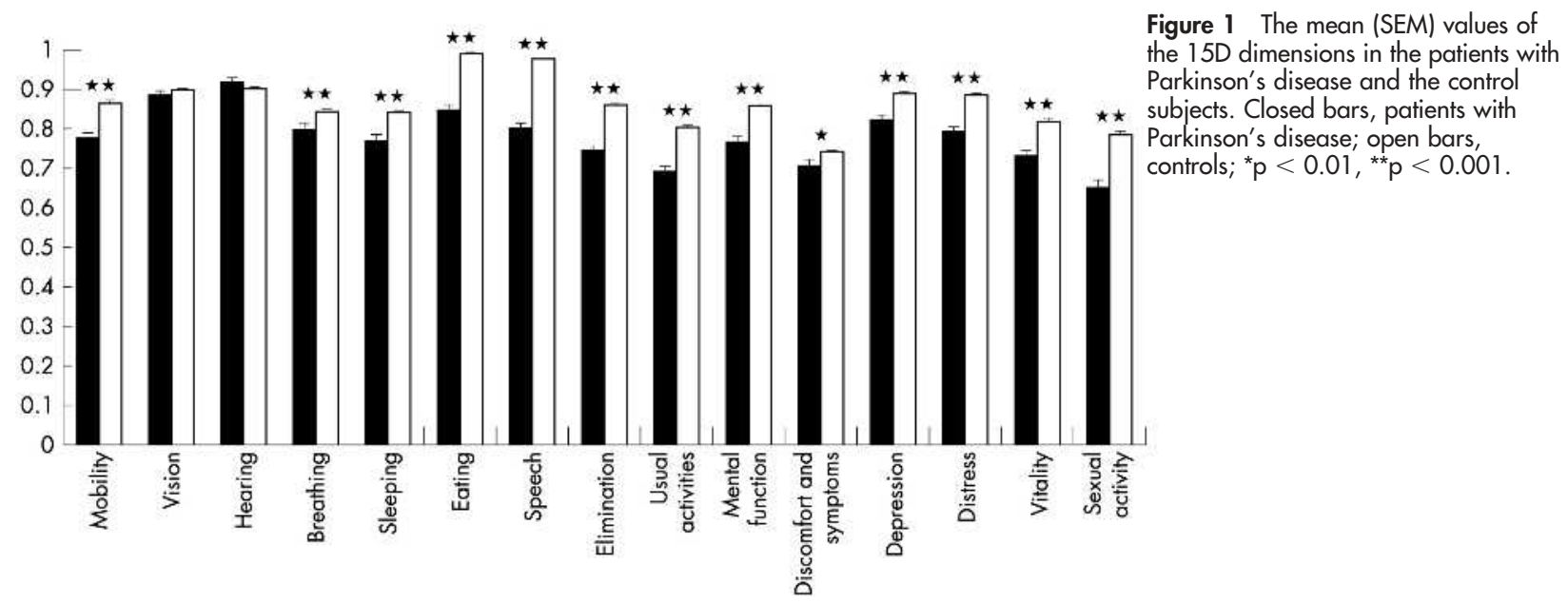

\begin{tabular}{|c|c|c|c|c|c|}
\hline & \multicolumn{3}{|l|}{ 15D questionnaire } & \multicolumn{2}{|l|}{ PDQ-39 questionnaire } \\
\hline & $\begin{array}{l}\text { PD patients } \\
\text { Mean (SD), N }\end{array}$ & $\begin{array}{l}\text { Controls } \\
\text { Mean (SD) }\end{array}$ & p Value & & Mean $(95 \% \mathrm{Cl}), \mathrm{N}$ \\
\hline 15D score & $0.77(0.13), 256$ & $0.86(0.12)$ & $<0.001$ & Summary score & $31.6(29.1$ to 34.0$), 167$ \\
\hline Mobility & $0.78(0.20), 257$ & $0.86(0.20)$ & $<0.001$ & Mobility & $32.9(28.6$ to 37.2$), 251$ \\
\hline Vision & $0.88(0.18), 258$ & $0.90(0.19)$ & 0.020 & $\mathrm{ADL}$ & 35.7 (31.9 to 39.5$), 256$ \\
\hline Hearing & $0.92(0.15), 257$ & $0.90(0.17)$ & 0.451 & Emotional well being & 33.5 (30.9 to 36.1 ), 203 \\
\hline Breathing & $0.80(0.23), 257$ & $0.84(0.23)$ & $<0.001$ & Stigma & 29.8 (26.6 to 32.9 ), 254 \\
\hline Sleeping & $0.77(0.21), 258$ & $0.84(0.20)$ & $<0.001$ & Social support & 22.3 (18.7 to 25.9$), 219$ \\
\hline Eating & $0.85(0.19), 258$ & $0.99(0.08)$ & $<0.001$ & Cognitions & 33.2 (30.4 to 35.9 ), 253 \\
\hline Speech & $0.80(0.20), 258$ & $0.97(0.10)$ & $<0.001$ & Communication & $22.7(20.5$ to 24.9$), 254$ \\
\hline Elimination & $0.74(0.22), 257$ & $0.86(0.21)$ & $<0.001$ & Bodily discomfort & 34.3 (31.8 to 36.7$), 254$ \\
\hline Usual activities & $0.69(0.22), 257$ & $0.80(0.24)$ & $<0.001$ & & \\
\hline Mental function & $0.76(0.21), 258$ & $0.85(0.19)$ & $<0.001$ & & \\
\hline Discomfort and symptoms & $0.70(0.21), 258$ & $0.74(0.24)$ & 0.007 & & \\
\hline Depression & $0.82(0.17), 258$ & $0.88(0.16)$ & $<0.001$ & & \\
\hline Distress & $0.79(0.18), 258$ & $0.88(0.16)$ & $<0.001$ & & \\
\hline Vitality & $0.73(0.17), 258$ & $0.82(0.18)$ & $<0.001$ & & \\
\hline Sexual activity & $0.65(0.30), 256$ & $0.78(0.30)$ & $<0.001$ & & \\
\hline
\end{tabular}

The 15D data of the patients with PD and the controls were compared using the Mann-Whitney $U$ test. $\mathrm{ADL}$, activities of daily life; Cl, confidence interval; PDQ-39, 39 item Parkinson's Disease Questionnaire.

variability of the data and associations between variables were checked. The explanatory variables were then divided into three different clusters. The most significant variables of these three clusters were then included in the final model. Two dimensions of 15D (vision and hearing) were not included in the dimension wise analysis because the aim was

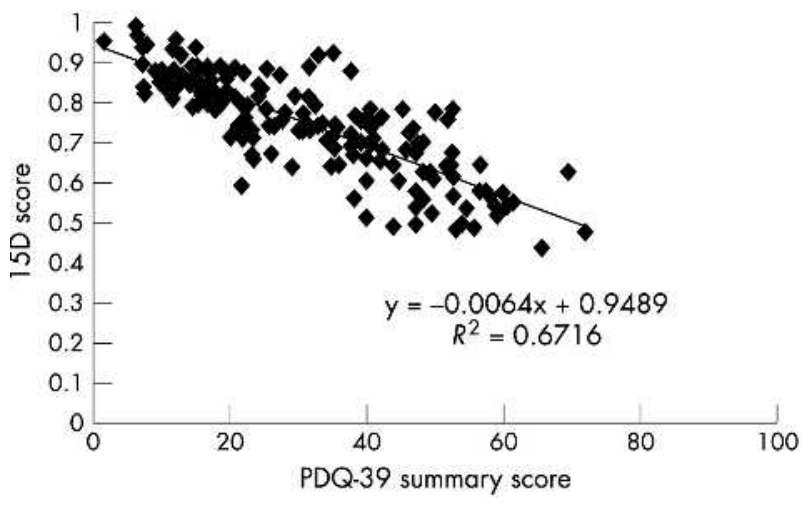

Figure 2 Correlation between the 15D score and the 39 item Parkinson's Disease Questionnaire (PDQ-39) summary score. to analyse the determinants of HRQoL that were typical for patients with PD. The scores of these two dimensions did not differ from the scores measured in control subjects.

Because of the great number of comparisons and correlations analysed and because no formal correction was used the threshold of significance was set at $\mathrm{p}<0.01$ for the comparisons between the patients with $\mathrm{PD}$ and controls subjects and at $\mathrm{p}<0.001$ for the correlation analysis. Statistical computing was performed with SAS System for Windows, release 6.12.

\section{RESULTS}

All except one of the patients with PD completed the study. Table 1 shows the demographic data and the Hoehn and Yahr stages of the patients with PD. Concomitant diseases were present in $71 \%$ of the patients with $\mathrm{PD}$, the most common being arterial hypertension $(17.6 \%)$, coronary heart disease ( $13.6 \%)$, diabetes mellitus (6.1\%), and arthrosis $(5.8 \%)$.

The response rate to the $15 \mathrm{D}$ questionnaire was $99.2 \%$, and $84.9 \%$ of the patients completed the questionnaire fully. When the few missing pieces of data were replaced, full data were available from 256 of the 260 patients (98.5\%). Table 2 shows the scores of the 15 different dimensions of the 15D questionnaire in the patients with $\mathrm{PD}$ and the control 
Table 3 Spearman's correlation coefficients of the disease specific PDQ-39 measures with the generic 15D quality of life measures

\begin{tabular}{|c|c|c|c|c|c|c|c|c|c|}
\hline \multirow[b]{2}{*}{ 15D } & \multicolumn{9}{|c|}{ PDQ-39 questionnaire } \\
\hline & $\begin{array}{l}\text { Single } \\
\text { index }\end{array}$ & Mobility & ADL & Emotional & Stigma & $\begin{array}{l}\text { Social } \\
\text { support }\end{array}$ & Cognitions & Communication & $\begin{array}{l}\text { Bodily } \\
\text { discomfort }\end{array}$ \\
\hline 15D score & $-0.825^{\star}$ & $-0.808^{*}$ & $-0.697^{*}$ & $-0.687^{*}$ & $-0.427^{*}$ & $-0.436^{*}$ & $-0.656^{*}$ & $-0.682^{*}$ & $-0.558^{*}$ \\
\hline Mobility & $-0.623^{*}$ & $-0.752^{*}$ & $-0.598^{*}$ & $-0.370^{*}$ & $-0.303^{*}$ & $-0.314^{*}$ & $-0.465^{*}$ & $-0.496^{*}$ & $-0.342^{*}$ \\
\hline Vision & $-0.527^{*}$ & $-0.539^{*}$ & $-0.453^{*}$ & $-0.409^{*}$ & -0.253 & $-0.307^{*}$ & $-0.453^{*}$ & $-0.440^{*}$ & $-0.289^{*}$ \\
\hline Hearing & $-0.311^{*}$ & $-0.261^{*}$ & $-0.214^{*}$ & $-0.273^{*}$ & -0.188 & -0.230 & $-0.326^{*}$ & -0.237 & -0.125 \\
\hline Breathing & $-0.520^{*}$ & $-0.489^{*}$ & $-0.354^{*}$ & $-0.408^{*}$ & $-0.326^{*}$ & $-0.366^{*}$ & $-0.337^{*}$ & $-0.441^{*}$ & $-0.391^{*}$ \\
\hline Sleeping & $-0.407^{*}$ & $-0.328^{*}$ & $-0.261^{*}$ & $-0.389^{*}$ & -0.196 & -0.102 & $-0.386^{*}$ & $-0.348^{*}$ & $-0.443^{*}$ \\
\hline Eating & $-0.528^{*}$ & $-0.510^{*}$ & $-0.582^{*}$ & $-0.370^{*}$ & $-0.345^{\star}$ & $-0.271^{*}$ & $-0.361^{*}$ & $-0.409^{*}$ & -0.247 \\
\hline Speech & $-0.445^{*}$ & $-0.380^{*}$ & $-0.405^{*}$ & $-0.294^{*}$ & -0.220 & -0.148 & $-0.407^{*}$ & $-0.596^{*}$ & $-0.262^{*}$ \\
\hline Elimination & $-0.442^{*}$ & $-0.437^{*}$ & $-0.314^{*}$ & $-0.381^{*}$ & -0.146 & -0.241 & $-0.448^{*}$ & $-0.378^{*}$ & $-0.285^{*}$ \\
\hline Usual activities & $-0.675^{*}$ & $-0.695^{*}$ & $-0.693^{\star}$ & $-0.483^{*}$ & $-0.373^{*}$ & $-0.402^{*}$ & $-0.464^{*}$ & $-0.538^{*}$ & $-0.397^{*}$ \\
\hline Mental function & $-0.401^{*}$ & $-0.349^{*}$ & $-0.331^{*}$ & $-0.286^{*}$ & -0.105 & -0.248 & $-0.535^{\star}$ & $-0.409^{*}$ & -0.227 \\
\hline Discomfort & $-0.429^{*}$ & $-0.392^{*}$ & $-0.283^{*}$ & $-0.441^{*}$ & -0.106 & -0.195 & $-0.339^{*}$ & $-0.280^{*}$ & $-0.553^{*}$ \\
\hline Depression & $-0.527^{*}$ & $-0.439^{*}$ & $-0.359^{*}$ & $-0.729^{*}$ & $-0.394^{*}$ & $-0.291^{*}$ & $-0.394^{*}$ & $-0.350^{*}$ & $-0.344^{*}$ \\
\hline Distress & $-0.441^{*}$ & $-0.325^{*}$ & $-0.280^{*}$ & $-0.660^{*}$ & $-0.324^{*}$ & $-0.256^{*}$ & $-0.373^{*}$ & $-0.320^{*}$ & $-0.332^{*}$ \\
\hline Vitality & $-0.618^{*}$ & $-0.609^{*}$ & $-0.504^{*}$ & $-0.533^{\star}$ & $-0.326^{*}$ & $-0.294^{*}$ & $-0.434^{*}$ & $-0.536^{*}$ & $-0.504^{*}$ \\
\hline Sexual activity & $-0.429^{*}$ & $-0.484^{*}$ & $-0.411^{*}$ & -0.209 & -0.151 & -0.160 & $-0.397^{*}$ & $-0.420^{*}$ & -0.236 \\
\hline
\end{tabular}

The correlations between dimensions of the questionnaires addressing corresponding aspects of quality of life are shown in bold. ${ }^{*} \mathrm{p}<0.001$.

ADL, activities of daily life; PDQ-39, 39 item Parkinson's Disease Questionnaire.

Table 4 Spearman's correlation coefficients of the UPDRS motor and ADL scores and various parkinsonian motor symptoms with the 15D and PDQ-39 quality of life measures

\begin{tabular}{|c|c|c|c|c|c|c|c|}
\hline & $\begin{array}{l}\text { UPDRS motor } \\
\text { score }\end{array}$ & $\begin{array}{l}\text { UPDRS ADL } \\
\text { score }\end{array}$ & Tremor & Rigidity & Hypokinesia & $\begin{array}{l}\text { Postural } \\
\text { instability }\end{array}$ & Gait disturbance \\
\hline \multicolumn{8}{|l|}{$15 \mathrm{D}$} \\
\hline $15 D$ score & $-0.55^{\star *}$ & $-0.69 * *$ & $-0.52^{* *}$ & $-0.36^{* *}$ & $-0.51^{* *}$ & $-0.58^{* *}$ & $-0.60^{* *}$ \\
\hline Mobility & $0.45^{\star *}$ & $0.55^{* *}$ & $0.43^{* *}$ & 0.20 & $0.41 * *$ & $0.49^{* *}$ & $0.63^{* *}$ \\
\hline Vision & $0.34^{* *}$ & $0.40^{* *}$ & $0.34^{* *}$ & 0.14 & $0.30^{* *}$ & $0.44^{* *}$ & $0.43^{* *}$ \\
\hline Hearing & 0.15 & $0.28^{* *}$ & 0.12 & 0.04 & 0.18 & 0.17 & 0.18 \\
\hline Breathing & 0.23 & $0.28^{* *}$ & 0.20 & 0.21 & 0.23 & 0.20 & $0.32^{\star \star}$ \\
\hline Sleeping & 0.20 & 0.25 & 0.18 & 0.21 & 0.27 & $0.31^{\text {** }}$ & 0.17 \\
\hline Eating & $0.38^{* *}$ & $0.52^{* \star}$ & $0.36^{* *}$ & 0.23 & $0.36^{* *}$ & $0.47^{* *}$ & $0.50^{* *}$ \\
\hline Speech & $0.33^{* *}$ & $0.49^{* *}$ & $0.32^{* *}$ & 0.24 & $0.33^{* *}$ & $0.44^{* *}$ & 0.29 \\
\hline Elimination & $0.38^{* *}$ & $0.36^{* *}$ & $0.38^{* *}$ & 0.22 & $0.31^{* *}$ & $0.35^{\star *}$ & $0.39^{* *}$ \\
\hline Usual activities & $0.55^{\star \star}$ & $0.69^{* *}$ & $0.52^{* *}$ & $0.34^{\star *}$ & $0.45^{\star *}$ & $0.52^{\star *}$ & $0.57^{\star *}$ \\
\hline Mental function & 0.21 & $0.30^{* *}$ & 0.21 & 0.06 & 0.19 & $0.29^{* *}$ & 0.26 \\
\hline Discomfort and symptoms & 0.17 & 0.25 & 0.15 & 0.17 & 0.18 & 0.18 & 0.17 \\
\hline Depression & $0.33^{\star *}$ & $0.37^{* *}$ & $0.31^{* *}$ & 0.25 & $0.35^{\star *}$ & $0.27^{\star *}$ & $0.29^{* \star}$ \\
\hline Distress & 0.19 & 0.22 & 0.17 & 0.20 & 0.18 & 0.11 & 0.14 \\
\hline Vitality & $0.40^{\star *}$ & $0.50^{* *}$ & $0.38^{* *}$ & $0.33^{* *}$ & $0.43^{* *}$ & $0.38^{\star *}$ & $0.41^{* *}$ \\
\hline Sexual activity & $0.51^{\star *}$ & $0.57^{* *}$ & $0.47^{* *}$ & $0.35^{\star \star}$ & $0.46^{* *}$ & $0.49^{* *}$ & $0.49^{* *}$ \\
\hline \multicolumn{8}{|l|}{ PDQ-39 } \\
\hline Summary score & $0.54^{* *}$ & $0.68^{* *}$ & $0.53^{\star *}$ & $0.35^{\star *}$ & $0.51^{* *}$ & $0.53^{* *}$ & $0.58^{* *}$ \\
\hline Mobility & $0.54^{* *}$ & $0.69^{* *}$ & $0.52^{* *}$ & $0.31^{* *}$ & $0.52^{* \star}$ & $0.59^{* *}$ & $0.64^{* *}$ \\
\hline$A D L$ & $0.57^{* *}$ & $0.72^{* *}$ & $0.56^{* *}$ & $0.35^{\star *}$ & $0.51^{* *}$ & $0.53^{* *}$ & $0.60^{* *}$ \\
\hline Emotional & $0.42^{\star \star}$ & $0.47^{\star *}$ & $0.40^{* *}$ & $0.32^{\star *}$ & $0.40^{* *}$ & $0.35^{\star \star}$ & $0.42^{\star *}$ \\
\hline Stigma & $0.31^{\text {** }}$ & $0.38^{* *}$ & $0.30^{* *}$ & 0.21 & $0.29^{* *}$ & 0.25 & $0.34^{* *}$ \\
\hline Social support & $0.31^{\text {** }}$ & $0.36^{* *}$ & $0.30^{* *}$ & 0.21 & 0.24 & 0.20 & $0.31^{\text {**}}$ \\
\hline Cognitions & $0.43^{* *}$ & $0.50^{\star *}$ & $0.41^{* *}$ & 0.23 & $0.38^{* *}$ & $0.41^{\text {** }}$ & $0.47^{\star \star}$ \\
\hline Communication & $0.48^{\star *}$ & $0.61^{* *}$ & $0.49^{* *}$ & $0.34^{\star *}$ & $0.43^{\star *}$ & $0.53^{\star *}$ & $0.50^{\star *}$ \\
\hline Bodily discomfort & 0.23 & $0.32^{\star *}$ & 0.25 & 0.22 & 0.26 & 0.23 & 0.21 \\
\hline
\end{tabular}

${ }^{* *} \mathrm{p} \leqslant 0.0001$

ADL, activities of daily living; PDQ-39, 39 item Parkinson's Disease Questionnaire; UPDRS, Unified Parkinson's Disease Rating Scale.

subjects. In the $15 \mathrm{D}$ profile, the scores of 13 of the 15 dimensions were significantly lower $(p<0.01)$ in the patients with $\mathrm{PD}$ compared with the control population, with only the scores of the dimensions of vision and hearing being equal in the two groups (fig 1).

The response rate to the PDQ-39 questionnaire was $98.5 \%$, but only $65.2 \%$ of patients answered the questions completely. Therefore, because no algorithm was available to replace the missing data, the full data were available for only 167 of the 260 patients (64.2\%). Table 2 presents the summary score and the scores of the subscales of the PDQ-39 measures.

The patients with incomplete 15D and PDQ-39 data were older than the patients with complete data (mean ages, $73.5 \mathrm{v}$
65.4 years), whereas the severity of PD or dementia did not affect the response rate. There were more women with missing data for both questionnaires. In cases with missing data in the 15D questionnaire the question on sexual activity was always omitted.

In the patients with full data in both HRQoL questionnaires $(\mathrm{n}=160)$ the 15D score correlated inversely with the summary score of PDQ-39 (fig 2). In addition, the subscales of the disease specific PDQ-39 instrument and the dimensions of the generic 15D dealing with similar aspects showed strong correlations except for "social support" (table 3).

Of the parameters evaluating the severity of the disease, the UPDRS motor score correlated with the 15D score on the 
Table 5 Comparison of HRQoL scores between patient groups identified by the Hoehn and Yahr stage, and presence or absence of motor fluctuations, depression, and dementia

\begin{tabular}{|c|c|c|c|}
\hline & \multicolumn{2}{|l|}{ 15D score } & PDQ-39 summary score \\
\hline & Mean (SD) & p Value & Mean (SD) $p$ Value \\
\hline \multicolumn{4}{|c|}{ Hoehn and Yahr stage } \\
\hline$<3$ & $0.81(0.1)$ & $<0.001$ & $26.7(13.7)<0.001$ \\
\hline$\geqslant 3$ & $0.65(0.1)$ & & $46.2(13.0)$ \\
\hline \multicolumn{4}{|c|}{ Motor fluctuations } \\
\hline Absent & $0.80(0.1)$ & $<0.001$ & $27.3(14.7)<0.001$ \\
\hline Present & $0.70(0.1)$ & & $41.3(14.4)$ \\
\hline \multicolumn{4}{|l|}{ Dementia } \\
\hline Absent & $0.78(0.1)$ & $<0.001$ & $29.8(15.6)<0.001$ \\
\hline Present & $0.65(0.1)$ & & $46.3(9.8)$ \\
\hline \multicolumn{4}{|l|}{ Depression } \\
\hline Absent & $0.81(0.1)$ & $<0.001$ & $27.9(15.6)<0.001$ \\
\hline Present & $0.68(0.1)$ & & $39.7(13.5)$ \\
\hline
\end{tabular}

The HRQoL scores of the patient groups were compared with the MannWhitney $U$ test.

HRQoL, health related quality of life; PDQ-39, 39 item Parkinson's Disease Questionnaire.

dimensions of mobility, vision, eating, speech, elimination, usual activities, depression, vitality, and sexual activity. The UPDRS ADL score correlated with all the 15 dimensions except for sleeping, discomfort, and distress, as did the Schwab and England score. Table 4 presents the correlation coefficients. The severity of the major manifestations of PD also correlated with the HRQoL measures (table 4). In addition, these correlations were analysed in the patients who completed both the 15D and the PDQ-39 to enable comparison of the results. Of the demographic variables, age correlated significantly with the 15D score $(r=-0.30$; $\mathrm{p}<0.001)$, with the mobility dimension score $(r=-0.39$; $\mathrm{p}<0.001)$, and also with the PDQ-39 summary score $(r=0.29 ; \mathrm{p}<0.001)$ and the mobility subscore $(r=0.40$; $\mathrm{p}<0.001)$.

The patients with more advanced PD (Hoehn and Yahr stage $\geqslant 3$ ) had lower HRQoL, as measured by both the 15D score and PDQ-39 summary score, than did those patients with milder PD. The presence of motor fluctuations, dementia, and depression resulted in poorer HRQoL scores (table 5).

In the stepwise regression analysis we entered age, sex, disease duration, and all the clinical factors that seemed to have an impact on the HRQoL measures in the correlation analysis. The explanatory variables were divided into three different clusters: the first included the demographics and the UPDRS items 18, 20, 22, 29, 30, and 31; the second included the demographics, the UPDRS ADL score, and the Schwab and England score; and the third included the demographics, the UPDRS motor score, and the Hoehn and Yahr stage. The most significant variables of these three clusters were then incorporated into the final model: age, sex, number of concomitant diseases, severity of depression and dementia, duration of PD from symptoms, presence or absence of motor fluctuations, the sum of the UPDRS items 20 (tremor) and 22 (rigidity), the UPDRS ADL and motor scores, and the Hoehn and Yahr stage. In the final model, the UPDRS ADL score explained most of the variation in the 15D score $\left(R^{2}=0.55\right)$ and in the summary score of PDQ-39 $\left(R^{2}=0.46\right)$. The final model including the UPDRS ADL score, depression, dementia, sex, Hoehn and Yahr stage, age, severity of tremor, and the number of concomitant diseases explained $65 \%$ of the variance of the utility index of 15D. Figure 3 shows the results of the stepwise multiple regression analysis.

\section{DISCUSSION}

PD compromises the HRQoL widely, as reflected by the generic instrument 15D, which demonstrated a clearly poorer quality of life in the patients compared with the control sample in 13 of the 15 dimensions evaluated. The results obtained by this generic tool correlate well with the disease specific PDQ-39 instrument, indicating that the 15D questionnaire is a valid and relevant measure of quality of life in PD.

The control group in our study consisted of a population based sample of age and sex matched subjects, which is thought to give a realistic view of the quality of life in PD because the prevalence of concomitant diseases presumably

\begin{tabular}{|c|c|c|c|c|c|c|c|c|c|c|c|c|c|}
\hline & Age & Sex & $\begin{array}{l}\text { Number } \\
\text { of olher } \\
\text { diseases }\end{array}$ & Dementia & Depression & $\begin{array}{l}\text { Duration } \\
\text { of PD from } \\
\text { symptoms }\end{array}$ & $\begin{array}{l}\text { Motor } \\
\text { fluctuations } \\
\text { present }\end{array}$ & $\begin{array}{l}\text { Tremor } \\
\text { at rest }\end{array}$ & Rigidity & $\begin{array}{l}\text { Motor } \\
\text { score }\end{array}$ & $\begin{array}{l}\text { Modified } \\
\text { HY }\end{array}$ & $A D L$ & Model $R^{2}$ \\
\hline $\begin{array}{l}\text { I5D score } \\
\text { Mobility } \\
\text { Vision } \\
\text { Hearing } \\
\text { Breathing } \\
\text { Sleeping } \\
\text { Eating } \\
\text { Speech } \\
\text { Elimination } \\
\text { Usual activities } \\
\text { Mental function } \\
\text { Discomfort and symptoms } \\
\text { Depression } \\
\text { Distress } \\
\text { Vitality } \\
\text { Sexual activity }\end{array}$ & $\begin{array}{c}\mathbf{0 . 0 1 8 2} \\
0.0287 \\
\text { N/A } \\
\text { N/A }\end{array}$ & $\begin{array}{l}0.0223 \\
0.0213 \\
0.0342 \\
0.0153 \\
0.0124 \\
0.0138\end{array}$ & $\begin{array}{c}0.0065 \\
0.0165 \\
\text { N/A } \\
\text { N/A } \\
0.0582 \\
0.0301 \\
0.0106\end{array}$ & $\begin{array}{c}\mathbf{0 . 0 0 4 5} \\
0.0417 \\
\text { N/A } \\
\text { N/A } \\
\\
0.0095 \\
0.0133 \\
0.0281 \\
0.0649\end{array}$ & $\begin{array}{c}0.0345 \\
\text { N/A } \\
\text { N/A } \\
0.0227\end{array}$ & $\begin{array}{l}0.0104 \\
\text { N/A } \\
\text { N/A }\end{array}$ & $\begin{array}{l}\text { N/A } \\
\text { N/A }\end{array}$ & $\begin{array}{l}0.012 \\
0.0075 \\
\text { N/A } \\
\text { N/A } \\
0.0245 \\
0.0156\end{array}$ & $\begin{array}{l}\text { N/A } \\
\text { N/A }\end{array}$ & $\begin{array}{l}\text { N/A } \\
\text { N/A }\end{array}$ & $\begin{array}{l}0.0122 \\
0.0193 \\
0.034 \\
0.0089\end{array}$ & $\begin{array}{l}0.5452 \\
0.4111 \\
\text { N/A } \\
\text { N/A } \\
0.084 \\
0.062 \\
0.4193 \\
0.3548 \\
0.2757 \\
0.4903 \\
0.1204 \\
0.0956 \\
0.0417 \\
0.2399 \\
0.4095\end{array}$ & $\begin{array}{l}0.6542 \\
0.5159 \\
\text { N/A } \\
\text { N/A } \\
0.1589 \\
0.1393 \\
0.4507 \\
0.4161 \\
0.2924 \\
0.5407 \\
0.2307 \\
0.2484 \\
0.3944 \\
0.186 \\
0.3311 \\
0.4702\end{array}$ \\
\hline $\begin{array}{l}\text { PDQ-39 summary score } \\
\text { Mobility } \\
\text { Activities of daily living } \\
\text { Emotional well-being } \\
\text { Stigma } \\
\text { Social support } \\
\text { Cognitions } \\
\text { Communication } \\
\text { Bodily discomfort }\end{array}$ & 0.0185 & $\begin{array}{l}0.0305 \\
0.0419 \\
0.0054 \\
0.0491\end{array}$ & $\begin{array}{c}0.0189 \\
0.009\end{array}$ & $\begin{array}{l}0.0139 \\
0.0317 \\
0.0109 \\
0.0108\end{array}$ & 0.1657 & $\begin{array}{l}0.0148 \\
0.0165\end{array}$ & 0.0094 & $\begin{array}{c}0.0225 \\
0.0219 \\
0.022\end{array}$ & & & 0.0398 & $\begin{array}{l}0.4613 \\
0.5693 \\
0.5977 \\
0.0773 \\
0.1457 \\
0.0595 \\
0.2266 \\
0.3834 \\
0.0666\end{array}$ & $\begin{array}{l}0.5603 \\
0.6758 \\
0.614 \\
0.3319 \\
0.1565 \\
0.0892 \\
0.3368 \\
0.4218 \\
0.1788\end{array}$ \\
\hline
\end{tabular}

The dependent variables and the explanatory variables in the final regression model. In each row, $R^{2}$ of significant explanatory variables is displayed; the variable that explained most of the variation is shadowed. The last column summarises the explanatory power of model $\left(R^{2}\right)$.

Figure 3 Results of the multiple regression analysis of 15D and 39 item Parkinson's Disease Questionnaire (PDQ-39) subscores. ADL, activities of daily life; PD, Parkinson's disease. 
is the same in these cohorts. Comparisons with healthy subjects would further accentuate the impaired degree of quality of life in patients with PD. ${ }^{10}$

Of the disease specific instruments developed for the assessment of HRQoL in PD, the content and construct validity and internal consistency of the PDQ-39 questionnaire ${ }^{4}$ are well established, ${ }^{23}$ and it was therefore chosen as the disease specific instrument in our study. The absolute scores of the PDQ-39 questionnaire in our patients were somewhat lower, reflecting better HRQoL than in some earlier studies, ${ }^{425}$ probably because of the younger age of the patients and the shorter duration of the disease in our cohort.

Much emphasis has been put on the development of the disease specific measures of HRQoL and the testing of their validity and reliability. ${ }^{45-28}$ Less attention has been paid to defining which clinical variables are most relevant for the variation in the quality of life. Peto et al found that rigidity and tremor were associated with lower HRQoL measured by PDQ-39. ${ }^{4}$ Recently, two studies have used multiple regression analysis to identify the clinical features and demographic variables predicting HRQOL. ${ }^{6}{ }^{10}$ In the study of Karlsen et al depressive symptoms, sleep problems, and a low Schwab and England score were the variables that had the most detrimental effect on overall quality of life, with the full model explaining 54\% of the total Nottingham Health Profile $^{29}$ score variance. ${ }^{10}$ Accordingly, Schrag et al reported a stepwise regression model where the Beck's Depression Inventory score, ${ }^{30}$ the Schwab and England score, the severity of postural instability, and the Mini Mental State Examination (MMSE) score ${ }^{31}$ explained $72 \%$ of the variance of the PDQ-39 summary index. ${ }^{6}$ In our study, the ADL score of the UPDRS was strongly related to HRQoL, measured both with the 15D score and the PDQ-39 summary score. Moreover, the severity of depression contributed to the deterioration of the quality of life in patients with PD, compromising especially the vitality and emotional aspects of life. The association of depression with the HRQoL in our patients with PD would probably have been stronger if a formal depression scale had been used.

Co-linearity is a potential source of error in regression analysis. Therefore, the disability evaluated with the Schwab and England score and the UPDRS ADL score was analysed in a separate regression analysis, and the UPDRS ADL score was found to have a stronger predictive value for HRQoL. Furthermore, it is possible that the severity of the various parkinsonian symptoms did not arise as explanatory factors of the quality of life because they are parts of the clinical assessment scales included in the multiple regression analysis.

Earlier studies using generic instruments to compare the HRQoL in parkinsonian patients with healthy subjects and patients with other diseases have reported that PD has a considerable impact on HRQoL, with the negative influence being highest for physical mobility, emotional reactions, social isolation, and energy. ${ }^{32}$ However, the problem with generic instruments is that many of them have not been specifically tested and validated in patients with PD and their feasibility in elderly patient groups is relatively low. ${ }^{33}$ The 15D score and most of the 15 dimensions of the instrument correlated strongly with the severity of the disease measured with the Hoehn and Yahr stage and the UPDRS motor and, especially, the ADL score. The 15D score also correlated strongly with the summary score of the disease specific PDQ39 instrument, as did the subscores of these instruments measuring similar aspects of HRQoL, indicating good convergent validity. Previously, the $15 \mathrm{D}$ has been used in several patient groups, in which it has shown good discriminatory power and responsiveness to change, ${ }^{15}{ }^{34}$ although its sensitivity to detect improvement brought about with PD medication or deterioration over time of the disease process remains to be tested.

The feasibility of the $15 \mathrm{D}$ in patients with $\mathrm{PD}$ was very high because full data were obtained from $84.9 \%$ of the patients, in contrast to the PDQ-39 instrument, where full data were obtained in only $64.2 \%$. Another generic HRQoL instrument, the EQ-5D, has been validated in PD. When compared with the $15 \mathrm{D}$, it is shorter and therefore easier and faster to complete, with the completion rate being $95 \%$ in patients with PD. ${ }^{7}$ However, the $15 \mathrm{D}$ is more comprehensive and covers-for example, sexual functioning-an item not included in the EQ-5D and the PDQ-39 questionnaires. ${ }^{35}$ Even if features like social and role functioning are missing in the 15D questionnaire, the instrument covers the areas most relevant to quality of life in $\mathrm{PD}$, such as leisure activities, housework, walking ability, communication, worries about the future, and bodily aches and pains. ${ }^{24}$ Two dimensionsvision and hearing-appear to be superfluous in the 15D questionnaire.

\section{CONCLUSIONS}

The 15D questionnaire seems to be suitable for patients with PD: it is not time consuming, it is easy to use, and the completion rate of the questionnaire is high. Despite its brevity, 15D covers the most important areas of the quality of life in this patient group and has a good sensitivity and validity. PD clearly compromises most of the 15 dimensions assessed in the 15D. Combined with the ADL score of the UPDRS, 15D is a useful indicator of HRQoL in patients with $\mathrm{PD}$ in clinical practice.

\section{Authors' affiliations}

T H Haapaniemi, K A Sotaniemi, Department of Neurology, University of Oulu, PO Box 25, 90029 Oulu, Finland

H Sintonen, Department of Public Health, University of Helsinki, 00014 Helsinki, Finland

E Taimela, Orion Pharma, 02101 Espoo, Finland

\section{APPENDIX}

\section{QUALITY OF LIFE QUESTIONNAIRE (15D) ${ }^{14}$}

Please read through all the alternative responses to each question before placing a cross $(x)$ against the alternative that best describes your present health status. Continue through all 15 questions in this manner, giving only one answer to each.

\section{Question 1. Mobility}

1. I am able to walk normally (without difficulty) indoors, outdoors, and on stairs.

2. I am able to walk without difficulty indoors, but outdoors and/or on stairs I have slight difficulties.

3. I am able to walk without help indoors (with or without an appliance), but outdoors and/or on stairs only with considerable difficulty or with help from others.

4. I am able to walk indoors only with help from others.

5. I am completely bed ridden and unable to move about.

\section{Question 2. Vision}

1. I see normally; that is, I can read newspapers and TV text without difficulty (with or without glasses).

2. I can read papers and/or TV text with slight difficulty (with or without glasses).

3. I can read papers and/or TV text with considerable difficulty (with or without glasses). 
4. I cannot read papers or TV text either with glasses or without, but I can see enough to walk about without guidance.

5. I cannot see enough to walk about without a guide; that is, I am almost or completely blind.

\section{Question 3. Hearing}

1. I can hear normally; that is, normal speech (with or without a hearing aid).

2. I hear normal speech with a little difficulty.

3. I hear normal speech with considerable difficulty; in conversation I need voices to be louder than normal.

4. I hear even loud voices poorly; I am almost deaf.

5. I am completely deaf.

\section{Question 4. Breathing}

1. I am able to breathe normally; that is, with no shortness of breath or other breathing difficulty.

2. I have shortness of breath during heavy work or sports, or when walking briskly on flat ground or slightly uphill.

3. I have shortness of breath when walking on flat ground at the same speed as others my age.

4. I get shortness of breath even after light activity-for example, washing or dressing myself.

5. I have breathing difficulties almost all the time, even when resting.

\section{Question 5. Sleeping}

1. I am able to sleep normally; that is, I have no problems with sleeping.

2. I have slight problems with sleeping-for example, difficulty in falling asleep, or sometimes waking at night.

3. I have moderate problems with sleeping-for example, disturbed sleep, or feeling I have not slept enough.

4. I have great problems with sleeping-for example, having to use sleeping pills often or routinely, or usually waking at night and/or too early in the morning.

5. I suffer severe sleeplessness-for example, sleep is almost impossible even with full use of sleeping pills, or staying awake most of the night.

\section{Question 6. Eating}

1. I am able to eat normally; that is, with no help from others.

2. I am able to eat by myself with minor difficulty (for example, slowly, clumsily, shakily, or with special appliances).

3. I need some help from another person in eating.

4. I am unable to eat by myself at all, so I must be fed by another person.

5. I am unable to eat at all, so I am fed either by tube or intravenously.

\section{Question 7. Speech}

1. I am able to speak normally; that is, clearly, audibly, and fluently.

2. I have slight speech difficulties-for example, occasional fumbling for words, mumbling, or changes of pitch.
3. I can make myself understood, but my speech isfor example, disjointed, faltering, stuttering, or stammering.

4. Most people have great difficulty understanding my speech.

5. I can only make myself understood by gestures.

\section{Question 8. Elimination}

1. My bladder and bowel work normally and without problems.

2. I have slight problems with my bladder and/or bowel function-for example, difficulties with urination, or loose or hard bowels.

3. I have marked problems with my bladder and/or bowel function-for example, occasional "accidents", or severe constipation or diarrhoea.

4. I have serious problems with my bladder and/or bowel function-for example, routine "accidents", or need of catheterisation or enemas.

5. I have no control over my bladder and/or bowel function.

\section{Question 9. Usual activities}

1. I am able to perform my usual activities (for example, employment, studying, housework, free time activities) without difficulty.

2. I am able to perform my usual activities slightly less effectively or with minor difficulty.

3. I am able to perform my usual activities much less effectively, with considerable difficulty, or not completely.

4. I can only manage a small proportion of my previously usual activities.

5. I am unable to manage any of my previously usual activities.

\section{Question 10. Mental function}

1. I am able to think clearly and logically, and my memory functions well.

2. I have slight difficulties in thinking clearly and logically, or my memory sometimes fails me.

3. I have marked difficulties in thinking clearly and logically, or my memory is somewhat impaired.

4. I have great difficulties in thinking clearly and logically, or my memory is seriously impaired.

5. I am permanently confused and disoriented in place and time.

\section{Question 11. Discomfort and symptoms}

1. I have no physical discomfort or symptoms-for example, pain, ache, nausea, itching, etc.

2. I have mild physical discomfort or symptoms-for example, pain, ache, nausea, itching, etc.

3. I have marked physical discomfort or symptomsfor example, pain, ache, nausea, itching, etc.

4. I have severe physical discomfort or symptoms-for example, pain, ache, nausea, itching, etc.

5. I have unbearable physical discomfort or symptomsfor example, pain, ache, nausea, itching, etc. 


\section{Question 12. Depression}

1. I do not feel at all sad, melancholic, or depressed.

2. I feel slightly sad, melancholic, or depressed.

3. I feel moderately sad, melancholic, or depressed.

4. I feel very sad, melancholic, or depressed.

5. I feel extremely sad, melancholic, or depressed.

\section{Question 13. Distress}

1. I do not feel at all anxious, stressed, or nervous.

2. I feel slightly anxious, stressed, or nervous.

3. I feel moderately anxious, stressed, or nervous.

4. I feel very anxious, stressed, or nervous.

5. I feel extremely anxious, stressed, or nervous.

\section{Question 14. Vitality}

1. I feel healthy and energetic.

2. I feel slightly weary, tired, or feeble.

3. I feel moderately weary, tired, or feeble.

4. I feel very weary, tired, or feeble, almost exhausted.

5. I feel extremely weary, tired, or feeble, totally exhausted.

\section{Question 15. Sexual activity}

1. My state of health has no adverse effect on my sexual activity.

2. My state of health has a slight effect on my sexual activity.

3. My state of health has a considerable effect on my sexual activity.

4. My state of health makes sexual activity almost impossible.

5. My state of health makes sexual activity impossible.

\section{REFERENCES}

1 Marinus J, Ramaker C, van Hilten JJ, et al. Health related quality of life in Parkinson's disease: a systematic review of disease specific instruments. J Neurol Neurosurg Psychiatry 2002;72:241-8.

2 Patrick D, Deyo R. Generic and disease-specific measures in assessing health status and quality of life. Med Care 1989;27(suppl):217-32.

3 Jenkinson C, Peto V, Fitzpatrick R, et al. Self-reported functioning and wellbeing in patients with Parkinson's disease: comparison of the Short-form Health Survey (SF-36) and the Parkinson's Disease Questionnaire (PDQ-39). Age Ageing 1995;24:505-9

4 Peto V, Jenkinson C, Fitzpatrick R. The development and validation of a short measure of functioning and well being for individuals with Parkinson's disease. Qual Life Res 1995:4:241-8.

5 De Boer AG, Wijker C, Fitzpatrick R, et al. Quality of life in patients with Parkinson's disease: development of a questionnaire. J Neurol Neurosurg Psychiatry 1996;61:241-8.

6 Schrag A, Jahanshahi M, Quinn N. What contributes to quality of life in patients with Parkinson's disease? J Neurol Neurosurg Psychiatry 2000;69:308-12.

7 Schrag A, Selai C, Jahanshahi M, et al. The EQ-5D-a generic quality of life measure -is a useful instrument to measure quality of life in patients with Parkinson's disease. J Neurol Neurosurg Psychiatry 2000;69:67-73.

8 Fahn S, Elton RL, and the members of the UPDRS Development Committee. UPDRS: Unified Parkinson's Disease Rating Scale. In: Fahn S, Marsden CD,
Calne DB, et al, eds. Recent developments in Parkinson's disease. New Jersey: Macmillan Health Care Information, 1987:153-64.

9 Hoehn MM, Yahr MD. Parkinsonism: onset, progression, and mortality Neurology 1967; 17:427-42.

10 Karlsen KH, Larsen JP, Tandberg E, et al. Influence of clinical and demographic variables on quality of life in patients with Parkinson's disease. J Neurol Neurosurg Psychiatry 1999;66:431-5.

11 Chrischilles EA, Rubenstein LM, Voelker MD, et al. The health burdens of Parkinson's disease. Mov Disord 1998;13:406-13.

12 Kuopio A-M, Marttila RJ, Helenius H, et al. The quality of life in Parkinson's disease. Mov Disord 2000;15:216-23.

13 Sintonen H. The 15D-measure of health-related quality of life. I. Reliability, validity, and sensitivity of its health state descriptive system. Working paper 41. Melbourne: National Centre for Health Program Evaluation, 1994

14 Sintonen H. The 15D-measure of health-related quality of life. II. Feasibility, reliability and validity of its valuation system. Working paper 42. Melbourne: National Centre for Health Program Evaluation, 1995 (http:// chpe.buseco.monash.edu.au).

15 Sintonen $\mathrm{H}$. The 15D instrument of health-related quality of life: properties and applications. Ann Med 2001;33:328-36.

16 Gibb WRG, Lees AJ. The relevance of the Lewy body to the pathogenesis of idiopathic Parkinson's disease. J Neurol Neurosurg Psychiatry 1988:51:745-52

17 Keränen T, Kaakkola S, Sotaniemi K, et al. Economic burden and quality of life impairment increase with severity of PD. Parkinsonism Relat Disord 2003;9:163-8

18 American Psychiatric Association. Diagnostic and statistical manual of mental disorders, 4th ed. Washington DC: American Psychiatric Association, 1994.

19 Arinen S, Häkkinen U, Klaukka T, et al. Health and the use of health services in Finland. Main findings in the Finnish Health Care Surveys 1995/96 and changes from 1987. In: Official statistics of Finland SVT. Helsinki: Health Care, 1998:5.

20 Malmivaara A, Häkkinen U, Aro T, et al. The treatment of acute low back pain-bed rest, exercises, or ordinary activity? N Engl J Med 1995:332:351-5

21 Kauppinen R, Sintonen $\mathrm{H}$, Tukiainen $\mathrm{H}$. One-year economic evaluation of intensive vs. conventional patient education and supervision for selfmanagement of new asthmatic patients. Respir Med 1998;92:300-7.

22 Stavem K. Reliability, validity and responsiveness of two multiattribute utility measures in patients with chronic obstructive pulmonary disease. Quality Life Res 1999:8:45-54

23 Marinus J, Ramaker C, van Hilten JJ, et al. Health related quality of life in Parkinson's disease: a systematic review of disease specific instruments. J Neurol Neurosurg Psychiatry 2002;72:241-8.

24 Fitzpatrick R, Peto V, Jenkison C, et al. Health-related quality of life in Parkinson's disease: a study of outpatient clinic attenders. Mov Disord 1997; 12:916-22

25 Martinez-Martin P, Frades Payo B and the Grupo Centro for Study of Movement Disorders. Quality of life in Parkinson's disease. Validation of the PDQ-39 Spanish version. J Neurol 1998;245(supp 1):S34-S38.

26 Calne S, Schultzer M, Mak E, et al. Validating a quality of life rating scale for idiopathic parkinsonism: Parkinson's impact scale. Parkinsonism Relat Disord 1996:2:55-61.

27 Van den Berg M. Leben mit Parkinson: Entwicklung und psychometrisch Testung des Fragenbogens PLQ. Neurologie and Rehabilitation 1998;4:221-6.

28 Bushnell DM, Martin ML. Quality of life and Parkinson's disease: translation and validation of the US Parkinson's disease questionnaire (PDQ-39). Qual Life Res 1999:8:345-50.

29 Hunt SM, McKenna SP, McEwen J, et al. The Nottingham Health Profile. Subjective health status and medical consultations. Soc Sci Med 1981;15A:221-9.

30 Beck AT, Rush AJP, Shaw BF, et al. Cognitive therapy of depression: a treatment manual. New York: Guilford, 1979.

31 Folstein MF, Folstein SE, McHugh PR. Mini-mental state: a practical method for grading the mental state of patients for the clinicians. J Psychiatr Res 1975; 12:189-98.

32 Karlsen KH, Larsen JP, Tandberg E, et al. Quality of life in patients with Parkinson's disease: a community based study. Eur J Neurosci 1998;5:1-8.

33 Brazier JE, Waiters SJ, Nicholl JP, et al. Using the SF-36 and Euroqol on an elderly population. Qual Life Res 1996;5:505-9.

34 Hawthorne G, Richardson J, Day NA. A comparison of the Assessment of Quality of Life (AQoL) with four other generic utility instruments. Ann Med $2001 ; 33: 358-70$

35 Damiano AM, McGrath MM, Willian MK, et al. Evaluation of a measurement strategy for Parkinson's disease: assessing patient health-related quality of life. Qual Life Res 2000;9:87-100. 